\title{
A APLICAÇÃO DE PROCEDIMENTOS DE CONSERVAÇÃO PREVENTIVA EM EXPOSIÇÕES TEMPORÁRIAS PRODUZIDAS PELO MUSEU DE ARTE DA PAMPULHA/ MG
}

\author{
Luciana Bonadio * \\ Universidade Federal de Minas Gerais
}

\section{RESUMO:}

A Conservação Preventiva realizada em exposições temporárias é uma das ações do setor de Conservação e Restauração do Museu de Arte da Pampulha, Belo Horizonte/ MG, para a preservação do acervo artístico institucional e do acervo de terceiros. Colocadas em prática a partir dos anos 1990 essas ações foram ampliadas em 2008, tendo como referência a publicação Conservación preventiva y procedimientos en exposiciones temporales (2008), além de passarem por várias revisões até os dias atuais. Desse modo, objetivamos: abordar as etapas realizadas pela área de Conservação e Restauração em exposições temporárias; relatar sobre o uso desses procedimentos pelo setor de Conservação e Restauração do Museu de Arte da Pampulha; apresentar a aplicação da metodologia publicada pelo Grupo Espanhol do IIC em uma exposição realizada pelo MAP; e, por fim, mostrar o trabalho do conservador-restaurador no percurso de construção de uma exposição, da pré até a pós-produção, passando pelo período expositivo.

\section{PALAVRAS-CHAVES:}

preservação, conservação preventiva, exposições temporárias, museu, conservador-restaurador

\begin{abstract}
The application of preventive conservation procedures in temporary exhibitions produced by the Museum of Art Pampulhal MG.
\end{abstract}

\begin{abstract}
:
The Preventive Conservation held in temporary exhibitions is one of the actions of the Conservation and Restoration sector in Museum of Art Pampulha, Belo Horizonte / MG, for the preservation of institutional art collection and the other collections. Put into practice from the 1990s these actions were expanded in 2008, with reference to the publication Conservación preventiva y procedimientos en exposiciones temporales (2008), and go through several revisions until today. In this way, we aimed to addressing the steps taken by the area of Conservation and Restoration in temporary exhibitions; report on the use of these procedures by the Conservation and Restoration sector of the Museum of Art Pampulha; present the application of the methodology published by the Spanish Group of the IIC in an exhibition held by the MAP; and, finally, show the work of the conservator-restorer in the course of building an exposure of the pre to post-production, through the exhibition period.
\end{abstract}

\section{KEY-WORDS:}

conservation, preventive conservation, temporary exhibitions, museum conservatorrestorer

\footnotetext{
* Luciana Bonadio é mestre em Arte e Tecnologia da Imagem pela Escola de Belas Artes da UFMG e especialista em Conservação-Restauração de Bens Culturais Móveis pela mesma escola. É professora do curso de graduação em Conservação-Restauração de Bens Culturais Móveis da EBA/ UFMG desde 20II e TNS em Conservação-Restauração do Museu de Arte da Pampulha onde atua e coordena o setor de Conservação e Restauração desde 2004.
} 
A aplicação de procedimentos de conservação preventiva em exposições temporárias produzidas pelo

Museu de Arte da Pampulha/ MG

\section{Introdução à Conservação Preventiva}

A Conservação Preventiva, área da Ciência da Conservação, aborda atividades direcionadas para a preservação e para a manutenção de acervos (museológicos, arquivísticos, bibliográficos, arqueológicos, etc.) sem a atuação direta sobre eles. Ela utiliza-se de procedimentos de prevenção incluindo a segurança, e de controle, os quais são focados nos edifícios e em seus entornos, e principalmente, na utilização criteriosa dos acervos. Esses procedimentos podem ser aplicados ao acervo acondicionado em reserva técnica, em exposição, e também, para obras em trânsito.

Essa disciplina, nascida no princípio dos anos 1980, estabeleceu-se no Brasil nos anos 1990 e hoje é a principal área da preservação de acervos em instituições museológicas e em exposições itinerantes. Em 1995, o cientista Gaël de Guichen publicou o artigo "Conservação preventiva: uma profunda mudança de mentalidade" pelo Conselho Internacional de Museus - ICOM. Nesse texto ele fala sobre a importância da conservação como meio de evitar a restauração, bem como a necessidade de mudar a forma de lidar com as coleções:

A conservação preventiva é um velho conceito no mundo dos museus, mas só nos últimos 10 anos que ela começou a se tornar reconhecida e organizada. Ela requer uma mudança profunda de mentalidade. Onde ontem se viam objetos, hoje devem ser vistas coleções. Onde se viam depósitos devem ser vistos edifícios. Onde se pensava em dias, agora se deve pensar em anos. Onde se via uma pessoa, devem ser vistas equipes. Onde se via uma despesa de curto prazo, se deve ver um investimento de longo prazo. Onde se mostram ações cotidianas, devem ser vistos programas e prioridades. A conservação preventiva busca assegurar a sobrevida das coleções. (Guichen, 1995: 2)'.

Desse modo, os museus começaram a olhar para as ações de conservação como principal meio de se tratar os acervos, evitando assim, as restaurações invasivas.

A conservação preventiva engloba o conhecimento da legislação de patrimônio; o controle ambiental passivo e ativo abarcando a iluminação, a temperatura, a umidade, os gases poluentes e os organismos vivos; a elaboração e execução de projetos relacionados à organização de acervos com definição de mobiliário, formas de acondicionamento de obras e controle ambiental; especificações para manuseio, embalagens e transporte. $O$ principal objetivo de todas essas ações é realizar a conservação dos objetos prezando pela sua permanência e longevidade?

Neste texto vamos nos deter somente aos procedimentos da conservação executados pelo conservador-restaurador. Os objetivos são: abordar as etapas realizadas pela área de Conservação e Restauração em exposições temporárias; relatar sobre o uso desses procedimentos pelo setor de Conservação e Restauração do Museu de Arte da Pampulha (CR/ MAP); apresentar a aplicação dessa metodologia em uma exposição realizada pelo MAP; e, por fim, mostrar o trabalho do conservador-restaurador no percurso expositivo, desde a pré-produção até a pós-produção, passando pelo período da exposição.

1 Tradução da autora deste texto.

2 Nos cursos de graduação em Conservação-restauração de bens culturais móveis, essa área tem se tornado obrigatória durante todo o curso, com disciplinas que abordam desde o gerenciamento da conservação (elaboração e execução de diagnóstico de conservação e montagem de programas de Conservação), passando pelo gerenciamento de riscos e incluindo as ações de salvaguarda. 


\section{A Conservação Preventiva em exposições temporárias no Museu de Arte da Pampulha}

O MAP atua com medidas de conservação preventiva em suas exposições desde os anos 1990. Até o ano de 2008, as atividades realizadas pelo setor de CR/ MAP em exposições temporárias eram restritas, compreendendo os procedimentos prévios de conservação-restauração das obras de arte, os laudos do estado de conservação e o acompanhamento das montagens das obras nos espaços expositivos.

A partir de 2008 o CR/ MAP, com o objetivo de aprimorar as ações, passou a atuar em duas frentes: uma com o acervo artístico acondicionado em reserva técnica, direcionada para a conservação preventiva e para a conservação-restauração, e a outra voltada para a conservação preventiva das exposições temporárias do acervo do Museu ou de terceiros. Focalizaremos a conservação das exposições temporárias, tendo como exemplo as atividades desenvolvidas durante os processos de desenvolvimento da exposição País Paisagem: uma expedição pelo Brasil através do acervo do Museu de Arte da Pampulha, produzida somente com obras do MAP.

A exposição País Paisagem, fez parte do projeto Museu Andante ${ }^{3}$, sendo produzida pelo próprio museu com o apoio do Centro Cultural Usiminas da cidade de Ipatinga, local onde foi realizada. Essa exposição, com o período expositivo de 19 de maio a 21 de agosto de 201 I, teve a curadoria de Renata Marquez ${ }^{4}$.

Segundo Marquez, esse projeto,

(...) investiga as artes visuais como o mediador cultural no processo de transformação da natureza em paisagem ou do país em paisagem. (...) As obras expostas materializam - em pintura, desenho, gravura, fotografia e audiovisual - a metamorfose e a metafísica da paisagem; elas atuam como exemplares das dinâmicas de transformação do nosso país em paisagem, são objetos culturais frutos das relações humanas de intervenção e criação de sentido no território (Museu de Arte da Pampulha, 20II.p.3).

Assim, Rochedo lluminado, a obra que inicia o percurso de País Paisagem, representa uma paisagem pintada a óleo, do final do século XIX, de autoria de João Baptista da Costa (1865-1926).A partir dessa introdução pela pintura acadêmica, a exposição se abre para as diversas paisagens dos séculos XX e XXI no Brasil, compondo os seguintes territórios: Jogos na relva, Tempos Modernos, Ventania, Brasília, Memória da paisagem e Cicloviaérea. A curadora sugere esse percurso e ainda comenta que há obras que "pertencem a dois territórios ao mesmo tempo, criando pontos de interseção nas fronteiras" (Museu de Arte da Pampulha, 201 I:7).

Não nos deteremos a explanar sobre cada território citado, pois o que nos interessa aqui,é a diversidade de materiais encontrados nas obras selecionadas e a sua preservação por meio de ações de conservação preventiva.

Começando pelas pinturas, podemos citar as seguintes técnicas: tinta a óleo sobre tela, tinta acrílica sobre tela; tinta acrílica sobre suporte rígido tipo Eucatex®; tinta automotiva sobre madeira e tinta acrílica sobre borracha. Seguindo

3 "O projeto Museu Andante busca levar periodicamente, partes selecionadas do acervo para fora do espaço do Museu, tornando acessível e aberta à visitação uma coleção que abarca várias décadas da produção artística brasileira" (Museu de Arte da Pampulha, 201 I: I).

4 Renata Marquez é doutora em Geografia, Professora de Análise Crítica da Arte na UFMG. Atua em teoria, crítica e práticas curatoriais na interface arte-arquitetura-geografia. Foi curadora do MAP em 201 I, realizando as curadorias dos projetos Arte Contemporânea 201 I e Museu Andante. Disponível em:www.geografiaportatil.org. Acesso em 30/06/20I4. 
A aplicação de procedimentos de conservação preventiva em exposições temporárias produzidas pelo

Museu de Arte da Pampulha/ MG

com as obras bidimensionais: desenho com pastel seco sobre papel; nanquim e aguada sobre papel; impressão em offset sobre papel; gravura em metal sobre papel; litografia sobre vinil; impressão em preto e branco sobre papel fotográfico fosco adesivado em PVC; impressão colorida sobre papel adesivado em suporte rígido tipo Eucatex® e cartão postal impresso a partir de fotolito. Nas esculturas temos: baixo relevo em cimento pintado com tinta guache; escultura em madeira; esculturas em pedra; esculturas em bambus pintados com tinta a óleo e vime trançado sobre bicicleta. E, por fim, dois audiovisuais. Essa variedade de suportes, materiais e técnicas, nos mostram a diversidade de obras datadas entre os anos 1950 e a primeira década dos 2000.

Com a seleção de obras feita pela curadoria nas mãos, o setor de CR/ MAP, iniciou as documentações e os procedimentos necessários para a preservação das obras, atuando em dois caminhos paralelos: a conservação preventiva e a conservação-restauração.

Os formulários e procedimentos das ações de conservação preventiva, elaborados pelo CR desde 2008, têm como referência a publicação Conservación preventiva y procedimientos en exposiciones temporales (2008). Essa publicação foi traduzida para o português e publicada pela Secretaria de Estado da Cultura de São Paulo, no ano de 2012.A edição ampliada, revisada e traduzida é fruto do III Encontro sobre Tratamento de Bens Culturais em Exposições Temporárias, promovido pelo Grupo Espanhol do International Institute for Conservation (IIC) e pela Pinacoteca do Estado de São Paulo ${ }^{5}$.A partir da sistematização e da normatização das atividades para a conservação em exposições temporárias vistas nesse evento, o CR/ MAP iniciou um processo de mudança em sua atuação, aplicando, em suas atividades cotidianas de produção de exposições temporárias, a metodologia abordada pela publicação citada, bem como promovendo alterações na forma de registro/ documentação dessas atividades. A seguir, apresentaremos a referida metodologia aplicada às ações de conservação-restauração em exposições temporárias realizadas pelo setor de CR/ MAP, exemplificando com a País Paisagem.

No entanto, antes de abordar os procedimentos, vale mencionar Paloma Muñoz-Campos, que faz referência às atividades da área de Conservação e Restauração para a construção de uma exposição.

(...) a Área de Conservação e Restauro é responsável por toda a informação que incide direta ou indiretamente no bem estar físico dos objetos, a qual deve estar bem relatada e completa. Isso se refere a aspectos como levantamento das dimensões, do peso, do histórico termo-higrométrico e de iluminação, tanto da peça quanto dos detaIhes relevantes presentes no Facility Report (Informe de Instalaciones na Espanha), as instruções para o manuseio seguro, as necessidades de transportes e embalagem, os detalhes dos suportes museográficos e as instruções para a montagem (Grupo Espanhol do IIC, 20I2: 78).

Diante dessa perspectiva, segue em forma de tabela, as atividades executadas e a documentação gerada pelo CR/ MAP em exposições temporárias. Em seguida, a cada etapa, comentaremos as atividades e a sua relevância para a preservação do acervo a ser mostrado.

5 O evento foi realizado em outubro de 2008 e teve a participação de instituições museológicas de todo o Brasil.A autora deste texto participou do referido evento representando o Museu de Arte da Pampulha. 


\section{Pré-Produção}

\begin{tabular}{|c|c|c|c|}
\hline ATIVIDADE & $\begin{array}{c}\text { DESCRIÇÃO DA } \\
\text { ATIVIDADE }\end{array}$ & $\begin{array}{l}\text { DOCUMENTAÇAO } \\
\text { PRODUZIDA PELO CR/ } \\
\text { MAP }\end{array}$ & $\begin{array}{c}\text { DOCUMENTO } \\
\text { ENCAMINHADO PARA }\end{array}$ \\
\hline \multirow[t]{2}{*}{$\begin{array}{l}\text { I. Análise do estado de } \\
\text { conservação das obras a } \\
\text { serem expostas }\end{array}$} & $\begin{array}{l}\text { I. Análise do estado de } \\
\text { conservação das obras e } \\
\text { determinação de quais obras } \\
\text { poderão ser expostas em }\end{array}$ & $\begin{array}{l}\text { I. Parecer técnico sobre o estado } \\
\text { de conservação de obras de arte. }\end{array}$ & $\begin{array}{l}\rightarrow \text { Curadoria e setor de } \\
\text { Museologia. }\end{array}$ \\
\hline & $\begin{array}{l}\text { decorrência do estado de } \\
\text { conservação de cada uma; quais } \\
\text { devem passar por procedimentos } \\
\text { de conservação curativa, } \\
\text { incluindo novos passe-partout e } \\
\text { moldura; e quais obras deverão } \\
\text { ser restauradas. }\end{array}$ & $\begin{array}{l}\text { 2. Lista de obras para os } \\
\text { procedimentos de conservação. }\end{array}$ & $\begin{array}{l}\rightarrow \text { Não há encaminhamento de } \\
\text { documentação desta atividade. } \\
\text { O documento permanece no } \\
\text { CR durante a exposição. }\end{array}$ \\
\hline $\begin{array}{l}\text { 2. Cronograma de } \\
\text { atividades da conservação. }\end{array}$ & $\begin{array}{l}2 \text { Após a análise das obras, o } \\
\text { conservador-restaurador elabora } \\
\text { um cronograma de atividades } \\
\text { para as etapas de pré-produção, } \\
\text { produção, período expositivo e } \\
\text { pós-produção. Esse deverá } \\
\text { contemplar o tempo necessário } \\
\text { para que as atividades aconteçam } \\
\text { sem atropelos. }\end{array}$ & $\begin{array}{l}\text { 3. Cronograma de atividades da } \\
\text { conservação. }\end{array}$ & $\begin{array}{l}\rightarrow \text { Curadoria, Setores de } \\
\text { Museologia e de Produção. }\end{array}$ \\
\hline $\begin{array}{l}\text { 3. Definição de materiais, } \\
\text { de embalagens e } \\
\text { transporte. }\end{array}$ & $\begin{array}{l}\text { 3. Definição dos materiais } \\
\text { necessários para a conservação e } \\
\text { para as intervenções de restauro, } \\
\text { se necessárias; os tipos e medidas } \\
\text { de passe-partout e molduras; os } \\
\text { tipos de embalagem e de } \\
\text { transporte e os profissionais a } \\
\text { serem contratados se necessário }\end{array}$ & $\begin{array}{l}\text { 4. Lista de materiais, passe-partout, } \\
\text { molduras e profissionais para } \\
\text { orçamentos. }\end{array}$ & $\rightarrow$ Setor de Produção. \\
\hline $\begin{array}{l}\text { 4. Análise do Facility } \\
\text { Report (Informe das } \\
\text { Instalações) da instituição } \\
\text { que receberá a exposição. }\end{array}$ & $\begin{array}{l}\text { 4. As instalações do espaço } \\
\text { expositivo que receberá as obras } \\
\text { deverão ser avaliadas. Se } \\
\text { necessário, deve-se fazer } \\
\text { proposta de alterações do local. }\end{array}$ & $\begin{array}{l}\text { 5. Parecer técnico sobre as } \\
\text { instalações. }\end{array}$ & $\rightarrow$ Setor de Museologia. \\
\hline $\begin{array}{l}\text { 5. Indicação das condições } \\
\text { específicas de conservação } \\
\text { para o transporte e para a } \\
\text { exposição. }\end{array}$ & $\begin{array}{l}\text { 5. Indicação: das condições } \\
\text { ambientais (T., U.R, Luz) para a } \\
\text { exposição e transporte das } \\
\text { obras; para a manipulação; dos } \\
\text { tipos de embalagens; do tipo de } \\
\text { transporte; da montagem e da } \\
\text { segurança. }\end{array}$ & $\begin{array}{l}\text { 6. Condições específicas de } \\
\text { conservação para empréstimos e } \\
\text { exposições. }\end{array}$ & $\rightarrow$ Setor de Museologia. \\
\hline $\begin{array}{l}\text { 6. Acompanhamento da } \\
\text { elaboração e análise final } \\
\text { do projeto expográfico*. }\end{array}$ & $\begin{array}{l}\text { 6. Acompanhamento da } \\
\text { elaboração do projeto } \\
\text { expográfico, juntamente com o } \\
\text { arquiteto, com o curador, com o } \\
\text { setor de Museologia e com a } \\
\text { equipe de produção. Durante } \\
\text { esse processo o conservador- } \\
\text { restaurador deve: prever os } \\
\text { riscos; detectar as áreas de } \\
\text { vulnerabilidade; abordar a } \\
\text { utilização de materiais } \\
\text { apropriados para o mobiliário } \\
\text { expográfico; informar o peso das } \\
\text { obras para o cálculo da } \\
\text { construção de paredes falsas; } \\
\text { sugerir a abertura de portas e } \\
\text { janelas para melhorar a ventilação } \\
\text { e o clima interno de acordo com } \\
\text { as necessidades das diferentes } \\
\text { tipologias de materiais das obras } \\
\text { a serem expostas; indicar a forma } \\
\text { adequada para a instalação da } \\
\text { iluminação artificial; definir áreas } \\
\text { de acessibilidade/ mobilidade. }\end{array}$ & $\begin{array}{l}\text { 7. Parecer técnico o projeto } \\
\text { expográfico. }\end{array}$ & $\begin{array}{l}\rightarrow \text { Curadoria, setores de } \\
\text { Museologia e de Produção. }\end{array}$ \\
\hline
\end{tabular}

I As atividades assinaladas com asterisco são lançadas no Sistema de Monitoramento de Atividades, Programas e Projetos da Fundação Municipal de Cultura (SMAPP/ FMC). Esse banco de dados possibilita à Divisão de Planejamento, Projetos e Avaliações da Fundação Municipal de Cultura (DVPPA/ FMC) avaliar as atividades dos projetos executadas durante uma gestão pública de quatro anos.

2 Quando as obras pertencerem a terceiros essa primeira vistoria acontecem juntamente com o setor de Museologia e com a Curadoria da exposição. 
A aplicação de procedimentos de conservação preventiva em exposições temporárias produzidas pelo

Museu de Arte da Pampulha/ MG

Na pré-produção o objetivo maior é encaminhar aos setores que realizarão a produção da exposição - Museologia e Produção, as condições de conservação de cada obra, incluindo o estado de conservação e os procedimentos que deverão ser realizados para que elas possam ser expostas sem correrem riscos de deterioração; os materiais e os serviços necessários para os procedimentos de conservação e de restauração e o cronograma de atividades do $C R$, que deverá integrar o cronograma geral da produção da exposição. Muñoz-Campos ressalta que

Não basta que o restaurador seja contratado para a montagem, é necessário que muito antes desse momento os especialistas em conservação tenham ditado uma série de pautas, as quais condicionarão divisões orçamentárias importantes no conjunto do investimento expositivo (Grupo Espanhol do IIC, 2012: 78.)

Com referência a esta citação, devemos lembrar que no MAP o conservador-restaurador faz parte do corpo técnico da instituição e participa desde o início da concepção da exposição. E que, juntamente com o setor de Museologia, primam pela preservação das obras.Ainda, como relata Muñoz-Campos,

Sem se mostrar catastrófica, a área de Conservação e Restauro deve alertar sobre a confluência de riscos em determinados estágios do projeto e velar pelo cumprimento dos padrões de qualidade em aspectos tais como os materiais empregados, a qualificação e capacitação dos profissionais que têm contato direto com as obras, ou o cumprimento das condições de temperatura e umidade exigidas pelo comodante (Grupo Espanhol do IIC, 2012:79).

Para a exposição País Paisagem a primeira ação do CR/ MAP foi analisar o estado de conservação das obras.A Curadoria e o setor de Museologia, guiados pela conservadora-restauradora responsável pelo acervo, discutiram sobre a participação de algumas obras ainda dentro das reservas técnicas, antes da emissão do parecer sobre o estado de conservação das obras a serem expostas.Assim, definimos aquelas que estavam em bom estado para a exposição, aquelas que passariam por intervenções de conservação-restauração podendo, posteriormente, serem expostas e as que por estarem muito fragilizadas não deveriam fazer parte da mostra.

Após a visita as RTs e enquanto uma análise mais detalhada das obras era executada pelo $C R$, reuniões do referido setor com a Curadoria e com a equipe da Expografia foram essenciais para o início do desenvolvimento do projeto expográfico. Realizamos, também, uma visita técnica ao espaço expositivo do Centro Cultural da Usiminas com o objetivo de conhecer as instalações locais. In loco, constatamos as condições ambientais; solicitamos a colocação de dimmer na iluminação artificial que foi avaliada por meio de testes prévios com medições de lux; apontamos os locais mais e menos frágeis para a colocação de determinados tipos de obras e definimos as áreas para o acondicionamento das obras em caixas no momento da chegada para a montagem. Dessa visita tivemos como resultado o parecer técnico sobre as instalações que foi encaminhado ao setor de Museologia do MAP.Vale ressaltar que especificamente para essa exposição, o setor de Museologia do MAP executou a produção ${ }^{6}$ juntamente com a equipe do Centro Cultural da Usiminas.

Ao finalizarmos as atividades da pré-produção, iniciamos as atividades da etapa da produção da exposição.

$6 \mathrm{~A}$ produção da exposição normalmente é realizada por uma equipe de produção. No entanto, para a País Paisagem, o setor de Museologia se encarregou também dessa atividade. 


\section{Produção}

\begin{tabular}{|c|c|c|c|}
\hline ATIVIDADE & DESCRIÇÃO DA ATIVIDADE & $\begin{array}{c}\text { DOCUMENTAÇAOO } \\
\text { PRODUZIDA PELO } \\
\text { CR/ MAP }\end{array}$ & $\begin{array}{l}\text { DOCUMENTO } \\
\text { ENCAMINHADO PARA }\end{array}$ \\
\hline $\begin{array}{l}\text { 7. Procedimentos de } \\
\text { restauração*. }\end{array}$ & $\begin{array}{l}\text { 7. Se a obra pertencente ao acervo do } \\
\text { MAP selecionada para a exposição for } \\
\text { extremamente importante e } \\
\text { necessária ao projeto curatorial, o } \\
\text { conservador-restaurador deverá } \\
\text { restaura-la. Esse procedimento poderá } \\
\text { acontecer com obras de terceiros, } \\
\text { mas somente em casos especiais. }\end{array}$ & $\begin{array}{l}\text { 8. Relatório de Conservação- } \\
\text { Restauração. }\end{array}$ & $\begin{array}{l}\rightarrow \text { Não há encaminhamento de } \\
\text { documentação desta atividade. } \\
\text { O documento permanece no } \\
\text { CR durante a exposição e } \\
\text { depois é entregue ao Centro } \\
\text { de Documentação e Pesquisa } \\
\text { do MAP. Ele será classificado na } \\
\text { série Acervo Artístico fazendo } \\
\text { parte da pasta do artista autor } \\
\text { da obra tratada. }\end{array}$ \\
\hline $\begin{array}{l}\text { 8. Procedimentos de } \\
\text { conservação curativa*. }\end{array}$ & $\begin{array}{l}\text { 8. As obras podem passar por } \\
\text { procedimentos de conservação } \\
\text { curativa como: limpeza; fixação de } \\
\text { camada pictórica; troca ou colocação } \\
\text { de passe-partout; troca ou colocação } \\
\text { de moldura; colocação de proteção no } \\
\text { verso de pinturas, etc. }\end{array}$ & $\begin{array}{l}\text { 9. Relatório de Conservaçẫo- } \\
\text { Restauração. }\end{array}$ & $\begin{array}{l}\rightarrow \text { Não há encaminhamento de } \\
\text { documentação desta atividade. } \\
\text { O documento permanece no } \\
\text { CR durante a exposição e } \\
\text { depois é entregue ao Centro } \\
\text { de Documentação e Pesquisa } \\
\text { do MAP (CEDOC/ MAP). Ele } \\
\text { será classificado na série } \\
\text { Acervo Artístico fazendo parte } \\
\text { da pasta do artista autor da } \\
\text { obra tratada. }\end{array}$ \\
\hline $\begin{array}{l}\text { 9. Elaboração dos } \\
\text { formulários e execução dos } \\
\text { laudos e conferências do } \\
\text { estado de conservação*. }\end{array}$ & $\begin{array}{l}\text { 9. Com as obras prontas para a } \\
\text { exposição são emitidos os laudos do } \\
\text { estado de conservação. Os laudos são } \\
\text { parte integrante do seguro, pois toda } \\
\text { obra deverá ser assegurada "prego-a- } \\
\text { prego", ou seja, desde o momento em } \\
\text { que ela sai da reserva técnica ou do } \\
\text { cedente, passando pelo período } \\
\text { expositivo até a sua devolução. O } \\
\text { profissional responsável pelo laudo, } \\
\text { preferencialmente um conservador- } \\
\text { restaurador, analisará as } \\
\text { características da obra, distinguindo-as } \\
\text { das deteriorações aparentes. O laudo } \\
\text { é o registro de como a obra se } \\
\text { apresentava no momento anterior a } \\
\text { sua embalagem para o transporte. } \\
\text { Após o transporte e a desembalagem } \\
\text { a obra deverá passar por uma } \\
\text { conferência, tendo como referência o } \\
\text { laudo realizado. Esse procedimento } \\
\text { será também executado antes da } \\
\text { reembalagem da obra para a saída da } \\
\text { exposição e também após a } \\
\text { desembalagem na devolução ao } \\
\text { cedente. }\end{array}$ & $\begin{array}{l}\text { 10. Laudo do estado de } \\
\text { conservação (coleta no } \\
\text { cedente). } \\
\text { II. Laudo do estado de } \\
\text { conservação (conferência na } \\
\text { chegada no cessionário). }\end{array}$ & $\begin{array}{l}\rightarrow \text { Não há encaminhamento de } \\
\text { documentação desta atividade. } \\
\text { O documento fica no CR como } \\
\text { referência para as vistorias } \\
\text { semanais realizadas no período } \\
\text { expositivo. }\end{array}$ \\
\hline $\begin{array}{l}\text { 10. Acompanhamento da } \\
\text { embalagem, da } \\
\text { desembalagem e da } \\
\text { reembalagem *. }\end{array}$ & $\begin{array}{l}\text { 10. A obra só será embalada/ } \\
\text { desembalada e reembalada, se o } \\
\text { laudo já tiver sido executado. O } \\
\text { conservador-restaurador deve } \\
\text { acompanhar a embalagem, a } \\
\text { desembalagem e a reembalagem das } \\
\text { obras que são realizadas pela } \\
\text { empresa de transporte especializada } \\
\text { em transportar obras de arte. } \\
\text { Durante esse procedimento, ele } \\
\text { indicará como a obra deverá ser } \\
\text { embalada, posicionada e colocada } \\
\text { dentro da caixa. As informações } \\
\text { passadas pelo conservador têm o } \\
\text { objetivo de evitar sinistros durante } \\
\text { o manuseio, a embalagem e o } \\
\text { transporte. }\end{array}$ & $\begin{array}{l}\text { 12. Documentação } \\
\text { fotográfica - registro do } \\
\text { processo de embalagem/ } \\
\text { desembalagem. }\end{array}$ & $\begin{array}{l}\rightarrow \text { Não há encaminhamento } \\
\text { de documentação desta } \\
\text { atividade. As fotografias ficam } \\
\text { no CR até o final da } \\
\text { exposição. }\end{array}$ \\
\hline
\end{tabular}




\begin{tabular}{|c|c|c|c|}
\hline ATIVIDADE & DESCRIÇÃO DA ATIVIDADE & $\begin{array}{l}\text { DOCUMENTAÇÄO } \\
\text { PRODUZIDA PELO CR/ } \\
\text { MAP }\end{array}$ & $\begin{array}{l}\text { DOCUMENTO } \\
\text { ENCAMINHADO PARA }\end{array}$ \\
\hline $\begin{array}{l}\text { II. Acompanhamento do } \\
\text { transporte (coleta)*. }\end{array}$ & $\begin{array}{l}\text { I IAcompanhamento da colocação } \\
\text { da obra dentro do caminhão, } \\
\text { indicando a posição que ela deverá } \\
\text { ser transportada e observando as } \\
\text { condições de limpeza e organização } \\
\text { do caminhão. } \\
\text { O protocolo de coleta e de chegada } \\
\text { são assinados pelas instituições } \\
\text { cedente e cessionária. }\end{array}$ & $\begin{array}{l}\text { 13. Documentação } \\
\text { fotográfica - registro do } \\
\text { transporte. } \\
\text { 14. Protocolo de coleta. } \\
\text { 15. Protocolo de chegada. }\end{array}$ & $\begin{array}{l}\rightarrow \text { Não há encaminhamento } \\
\text { de documentação desta } \\
\text { atividade. As fotografias ficam } \\
\text { no CR até o final da } \\
\text { exposição. } \\
\rightarrow \text { Setor de CR e instituição } \\
\text { cessionária. }\end{array}$ \\
\hline $\begin{array}{l}\text { 12. Acompanhamento da } \\
\text { montagem de obras no } \\
\text { espaço expositivo*. }\end{array}$ & $\begin{array}{l}\text { I2 Acompanhamento da montagem } \\
\text { de cada obra no espaço expositivo, } \\
\text { indicando a melhor forma de } \\
\text { manuseá-la e prezando pela sua } \\
\text { integridade física e conceitual. A } \\
\text { forma de montagem de uma obra, } \\
\text { seja de uma pintura ou de uma } \\
\text { instalação, deverá ser fiel às } \\
\text { instruções do autor. Assim, além de } \\
\text { cuidar do material, o conservador } \\
\text { deve estar sempre atento para que a } \\
\text { obra não seja alterada em sua } \\
\text { montagem, primando pela sua } \\
\text { originalidade. }\end{array}$ & $\begin{array}{l}\text { 16. Documentaçáo fotográfica } \\
- \text { registro do processo de } \\
\text { montagem. }\end{array}$ & $\begin{array}{l}\rightarrow \text { Não há encaminhamento } \\
\text { de documentação desta } \\
\text { atividade. As fotografias ficam } \\
\text { no CR até o final da } \\
\text { exposição. }\end{array}$ \\
\hline $\begin{array}{l}\text { 13. Elaboração das } \\
\text { instruções para a } \\
\text { conservação de obras de } \\
\text { arte*. }\end{array}$ & $\begin{array}{l}\text { 13. Antes da abertura da exposição } \\
\text { o conservador deverá passar ao } \\
\text { setor de Museologia todas as } \\
\text { instruções referentes à manutenção } \\
\text { do espaço expositivo visando a } \\
\text { conservação das obras durante o } \\
\text { período da exposição, como: modo } \\
\text { de execução da limpeza dos espaços } \\
\text { expositivos; controle de aberturas } \\
\text { de portas e janelas pelos guarda- } \\
\text { salas e informações referentes às } \\
\text { especificidades de cada obra, } \\
\text { principalmente das instalações e } \\
\text { obras em novas mídias. }\end{array}$ & $\begin{array}{l}\text { 17. Instruções para a } \\
\text { conservação de obras de arte } \\
\text { em exposições temporárias. }\end{array}$ & $\rightarrow$ Setor de Museologia. \\
\hline
\end{tabular}

Na etapa de Produção de País Paisagem organizamos duas frentes de trabalho: parte da equipe passou a dedicar-se às montagens de obras em molduras e passe-partout, além de preparar e executar os laudos do estado de conservação, e parte, voltou-se para a conservação-restauração de pinturas e esculturas.A maioria das obras apresentava-se com sujidades superficiais, as quais foram limpas, e apenas uma escultura e duas pinturas passaram por intervenções de restauração ${ }^{7}$.

Com as obras preparadas para a exposição e com os devidos laudos do estado de conservação realizados, acompanhamos as embalagens de cada uma. As obras foram embaladas e colocadas em caixas de madeira especialmente construídas para cada uma e de acordo com as recomendações encaminhadas na etapa de pré-produção ao setor de Museologia ${ }^{8}$. Nas caixas, por questão de segurança, figuravam em etiqueta de papel somente o nome da instituição, o título da mostra e o número da obra na lista de obras, além dos ícones de segurança. Elas foram posicionadas, organizadas e imobilizadas dentro do caminhão

7 tempo para a execução de todas essas atividades era insuficiente e para poder realizá-las de forma segura e ágil, contamos com o apoio do setor de Conservação e Restauração do Museu Histórico Abílio Barreto, que também é um equipamento cultural da FMC.

8 Essa atividade é de responsabilidade do setor de Produção, mas como dito anteriormente, quem realizou toda a produção técnica da exposição foi o setor de Museologia e o Centro Cultural da Usiminas. 
e seguiram para Ipatinga. Solicitamos um caminhão com suspensão pneumática e elevador hidráulico (plataforma) para que as obras sofressem o menos possível com os impactos e as trepidações na estrada.

Reafirmamos a importância de uma transportadora especializada em transporte de obras de arte para a realização do traslado das obras. Com caminhão apropriado e pessoal treinado para manuseio e embalagens, garantimos um transporte seguro e livre de imprevistos.

As atividades da conservação preventiva na pré-produção e na produção são de fundamental importância para a preservação das obras em trânsito. As recomendações, procedimentos e documentações devem auxiliar e garantir que sinistros não aconteçam. A troca de informações deve se dar de forma clara, objetiva e de acordo com o fluxograma proposto no início dos trabalhos.

Da preparação da exposição, passando pela montagem até a abertura para o público, as ações devem ser executadas por cada área de competência: "Gestão/ organização, Curadoria/ Científica, Comunicação/ Educação, Conservação/ Restauro e Design/ Montagem" (Grupo Espanhol do IIC, 20I2: 33). Dessa maneira, com a participação de profissionais especializados para cada área, com funções e responsabilidades distintas é possível construir e manter uma exposição sem que imprevistos aconteçam.

\section{Período Expositivo}

\begin{tabular}{|c|c|c|c|}
\hline ATIVIDADE & DESCRIÇÃO DA ATIVIDADE & $\begin{array}{l}\text { DOCUMENTAÇAOO } \\
\text { PRODUZIDA }\end{array}$ & $\begin{array}{c}\text { DOCUMENTO } \\
\text { ENCAMINHADO PARA }\end{array}$ \\
\hline $\begin{array}{l}\text { 14. Vistorias das } \\
\text { obras expostas*. }\end{array}$ & $\begin{array}{l}\text { 14. Todas as obras deverão ser } \\
\text { vistoriadas diariamente, e de forma } \\
\text { mais detalhada, uma vez por semana. } \\
\text { Essa vistoria detalhada acontece } \\
\text { sempre às segundas-feiras, quando o } \\
\text { espaço expositivo está fechado para } \\
\text { o público devido às manutenções da } \\
\text { instituição. O conservador confere } \\
\text { obra por obra utilizando-se do } \\
\text { laudo como referência. Caso } \\
\text { aconteça alguma alteração na obra, } \\
\text { ela deverá ser anotada e se for } \\
\text { necessário, a obra deverá ser } \\
\text { retirada da exposição para } \\
\text { manutenção. }\end{array}$ & 18. Vistorias. & $\begin{array}{l}\rightarrow \text { Não há encaminhamento de } \\
\text { documentação desta atividade. } \\
\text { O documento fica no CR até o } \\
\text { final da exposição. }\end{array}$ \\
\hline $\begin{array}{l}\text { I5. Higienização } \\
\text { das obras } \\
\text { expostas*. }\end{array}$ & $\begin{array}{l}\text { 15. Durante o período expositivo as } \\
\text { obras deverão ser higienizadas } \\
\text { somente com trincha, para que o } \\
\text { acúmulo de poeira e particulados } \\
\text { não as deteriorem. A higienização } \\
\text { acontecerá somente às segundas- } \\
\text { feiras, após as vistorias. }\end{array}$ & 18. Vistorias. & $\begin{array}{l}\rightarrow \text { Não há encaminhamento de } \\
\text { documentação desta atividade. } \\
\text { As fotografias ficam no CR até } \\
\text { o final da exposição. }\end{array}$ \\
\hline
\end{tabular}

As vistorias semanais das obras de País Paisagem foram realizadas pela equipe do Centro Cultural da Usiminas. O CR/ MAP fez uma vistoria detalhada durante o período expositivo, com higienização e conferência da iluminação.

Observamos que, apesar do local da exposição ter poucas aberturas para a área externa do edifício, a entrada de particulados foi maior que a esperada. $A$ causa é a localização do Centro Cultural pela proximidade com áreas de mineração e de transporte de minério de ferro. Além disso, nada mais foi constatado e pequenos ajustes foram realizados na iluminação da parede onde se encontravam algumas obras sobre papel, mais frágeis à luz. Com o período expositivo finalizado, iniciamos os procedimentos da pós-produção 
A aplicação de procedimentos de conservação preventiva em exposições temporárias produzidas pelo

Museu de Arte da Pampulha/ MG

\section{Pós-produção}

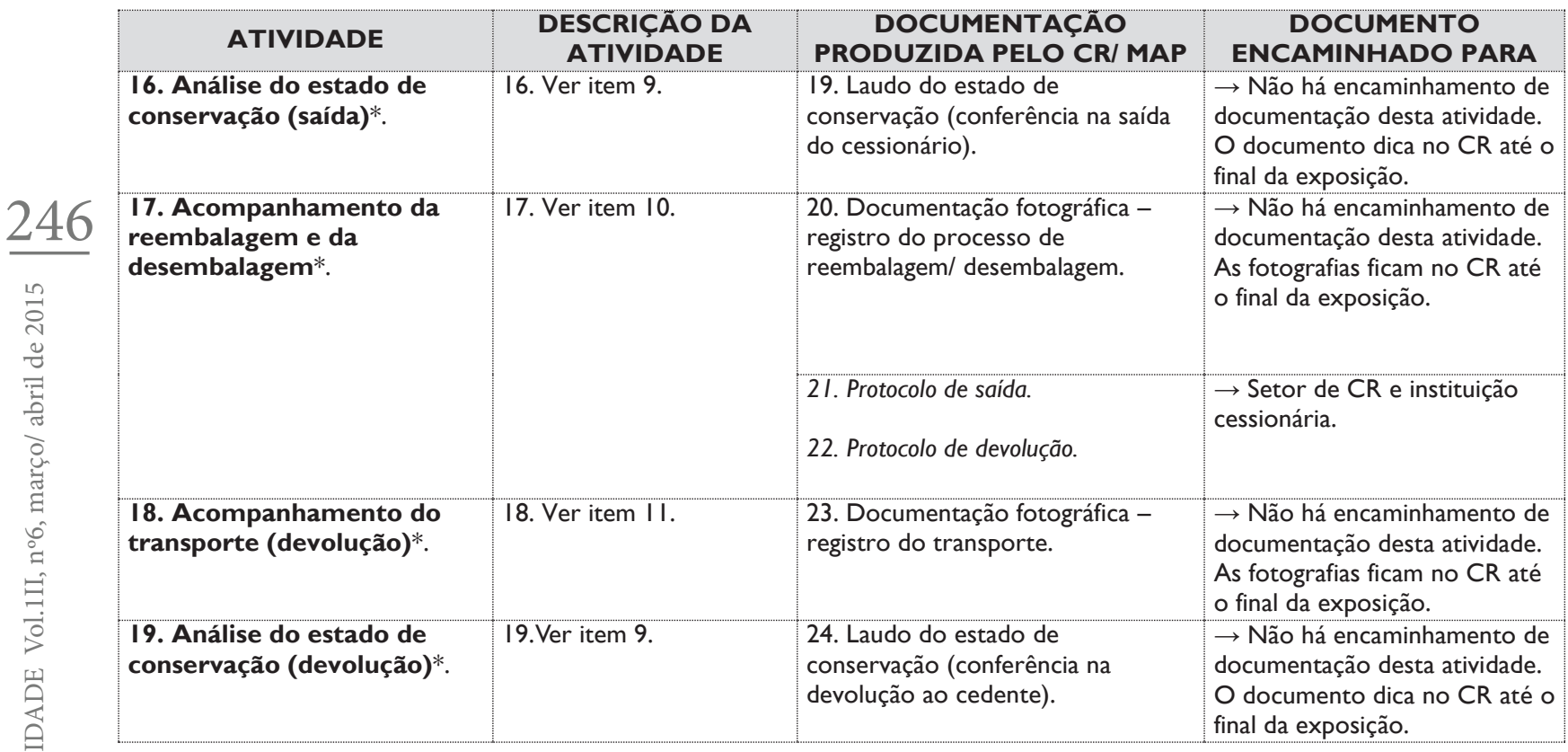

$\mathrm{Na}$ exposição que utilizamos como exemplo não ocorreram sinistros. Mas, se em algum momento houver um sinistro, devemos realizar a seguinte atividade:

\begin{tabular}{|l|l|l|l|l|}
\hline ETAPA & ATIVIDADE & \multicolumn{1}{|c|}{$\begin{array}{c}\text { DESCRIÇÃO DA } \\
\text { ATIVIDADE }\end{array}$} & $\begin{array}{l}\text { DOCUMENTAÇA } \\
\text { O PRODUZIDA } \\
\text { PELO CR/ MAP }\end{array}$ & $\begin{array}{l}\text { DOCUMENTO } \\
\text { ENCAMINHAD } \\
\text { O PARA }\end{array}$ \\
\hline & $\begin{array}{l}\text { 20. Análise do } \\
\text { estado de } \\
\text { conservação da } \\
\text { obra - ocorrência*. }\end{array}$ & $\begin{array}{l}\text { 20. Em caso de sinistros } \\
\text { durante o período expositivo, o } \\
\text { conservador deverá emitir o } \\
\text { laudo do estado de } \\
\text { conservação, relatando a } \\
\text { ocorrência detalhadamente. E o } \\
\text { setor de Museologia acionará o } \\
\text { seguro. }\end{array}$ & $\begin{array}{l}\text { 25. Laudo do estado } \\
\text { de conservação } \\
\text { (sinistro). }\end{array}$ & $\begin{array}{l}\rightarrow \text { Setor de } \\
\text { Museologia. }\end{array}$ \\
\hline
\end{tabular}

A documentação produzida durante todo o processo citado tem $\circ$ objetivo de registrar os procedimentos como forma de assegurar a conservação realizada e também como forma de termos ao final da exposição uma memória do processo do ponto de vista da conservação. Com as obras devolvidas ao cedente, demos por encerrada a ação do CR/ MAP e a documentação gerada foi encaminhada ao CEDOC/ MAP. Essa documentação passou a fazer parte do dossiê da exposição, que integra a série Exposições. Ao entrar no CEDOC, a documentação é processada e liberada para o acesso ao público/ consulente.

Nesse processo, e também no dia-a-dia do CR/ MAP, prezamos pela realização das etapas relatadas, ressaltando a importância de todas essas atividades, da documentação gerada e do cumprimento da preservação das obras em exposições e em trânsito.

A mudança de posicionamento proposta pelo setor CR há seis anos gerou inicialmente discussões, resistências e rupturas. Mas, tendo a corroboração 
das chefias da instituição para a implementação dessa metodologia, persistimos. E hoje, esses procedimentos já estão absorvidos por toda a equipe técnica do Museu que colabora com críticas e ajustes, aprimorando a nossa atuação.

Com o planejamento dessas atividades bem elaborado e executado, sem fadigas e sem estresse, deixamos de colocar em risco as obras e também a nossa saúde e bem-estar.

Em consideração final, constatamos o envolvimento de toda a equipe técnica do MAP, com sua dedicação, competência e adoção de procedimentos que reforçam um dos principais objetivos do Museu de Arte da Pampulha: a preservação do acervo artístico dessa instituição.

\section{Referências}

ARECHAVALA, Fernando, FERNANDEZ, Charo, MUÑOZ-CAMPOS, Paloma e TAPOL, Benoit de. Conservación preventiva y procedimientos en exposiciones temporales. Madrid: Grupo Español del International Institute for Conservation of Historic and Artistic Works e Fundación Duques de Soria, 2008.

GRUPO ESPANHOL DO IIC - International Institute for Conservation (org.). Conservação preventiva e procedimentos em exposições temporárias. São Paulo: Secretaria de Estado da Cultura de São Paulo, 2012.

GUICHEN, Gaël de. La Conservation Préventive: un changement profond de mentalité. Study series, Bruxelas: ICOM-CC/ULB, v.I, n.I, p.4-5, 1995. Disponível em: http://icom.museum/study_series_pdf/I_icom-cc.pdf. Acesso em 26/06/2014.

MUSEU DE ARTE DA PAMPULHA. País Paisagem: Uma expedição pelo Brasil através do acervo do Museu de Arte da Pampulha. Belo Horizonte: Museu de Arte da Pampulha, 2012. Catálogo de exposição.

Artigo recebido em junho de 20I4. Aprovado em agosto de 2014 
248

음

ซั

공

클

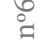

$\exists$

띤

空

z

붕

翔

$\infty$

嵌

焉 